\title{
The Value of Trust and Fairness in Alliances: An Economic Perspective
}

\author{
Kiridaran Kanagaretnam1, Alex Thevaranjan² \\ ${ }^{1}$ Schulich School of Business, York University, Toronto, Canada \\ ${ }^{2}$ Whitman School of Management, Syracuse University, Syracuse, USA \\ Email: KKanagaretnam@schulich.yorku.ca, athevara@syr.edu
}

How to cite this paper: Kanagaretnam, K. \& Thevaranjan, A. (2021). The Value of Trust and Fairness in Alliances: An Economic Perspective. Theoretical Economics Letters, 11, 166-185. https://doi.org/10.4236/tel.2021.112012

Received: January 14, 2021

Accepted: March 27, 2021

Published: March 30, 2021

Copyright (c) 2021 by author(s) and Scientific Research Publishing Inc. This work is licensed under the Creative Commons Attribution International License (CC BY 4.0).

http://creativecommons.org/licenses/by/4.0/ cc (i) Open Access

\begin{abstract}
In this paper, we develop an analytical model to illustrate the role of trust and fairness in alliances and quantify their economic value to alliance partners. We show that alliance profits and the individual firms' profits are greatest when partners trust and deal fairly with each other. Moreover, trusting and fair dealing partners benefit the most from the synergies of joint production. We also show that when partners do not trust each other, the alliance profits are reduced by a large amount. The alliance potential is further destroyed if partners do not deal fairly with each other in addition to not trusting each other. The lack of trust and fair play causes firms to fight for control. The fight may result in conflict between the two partners or the emergence of a dominant partner. In the dominant partner case, we show that only alliances with high levels of synergy will be formed. But even then, the dominant partner will realize only a small portion of the benefits from synergy.
\end{abstract}

\section{Keywords}

Business Alliances, Trust, Fairness, Mathematical Modelling, Synergy

\section{Introduction}

Synergies between firms can be exploited by the formation of alliances (Parkhe, 1998). However, the potential for opportunistic actions of alliance partners poses a serious threat to the formation of alliances. Factors that can mitigate opportunistic actions and encourage the realization of the inter-firm synergies are not well understood. Prior economic literature has focused mainly on developing external controls such as incentive contracts and monitoring mechanisms to moderate the opportunism of alliance partners (e.g., Parkhe, 1993; Parkhe, 1998; Birn- 
birg, 1998; Lerner \& Merges, 1998). Our objective is to show the importance of some relationship factors between alliance partners in the realization of interfirm synergies. Accordingly, in this paper, we develop an analytical model to illustrate the role of trust and fairness in alliances and derive their economic value to alliance partners.

Strategic alliances bring together otherwise independent firms to share resources in product design, production, marketing, and/or distribution. Such alliances are becoming prevalent as competitive pressures force firms to adopt flexible and more focused organizational structures (Chan et al., 1997). Firms within alliances collaborate, while competing with other similar groups (Chang et al., 2020). The return on successful alliances can be significant enough to justify a substantial investment of resources in their advance planning. When structured carefully, alliances can contribute to the growth of firms across industries. On the other hand, alliances amongst firms often fail (Gomes et al., 2016; Zineldin et al., 2015). The median life span for alliances is only seven years, and nearly $80 \%$ of joint ventures-one of the most common alliance structures ultimately end in a sale by one of the partners (Bleeke \& Ernst, 1995).

Management Scholars and practitioners are increasingly concerned with understanding what makes some alliances work so well over time while others flounder (Ariño et al., 2001; Ireland et al., 2002; Kale \& Sing 2009; Li et al., 2017; Russo \& Cesarini, 2017). The ability to rely on mutual trust and forbearance constitutes a critical ingredient by which partners weather the conflicts stemming from possible opportunistic actions, economic and competitive changes, as well as shifts in corporate priorities (Ring \& Van de Ven, 1992; Parkhe, 1998; Poppo et al., 2016). Furthermore, consideration of fairness is also an important determinant in the development of long-term cooperative relationships (Kumar et al., 1995; Luo, 2005; Krishnan et al., 2006). Dwyer et al. (1987) regard fairness in interactions as necessary for developing trust between business partners. Anderson and Weitz (1989) observe that suppliers with a reputation for fairness engender greater trust and expectation of continuity. These observations are confirmed by Croonen (2010). Trusting relationships are built with systems that strive both to compensate the partners fairly for their contributions and to resolve differences in a manner that the partners perceive as fair (Kumar, 1996).

Mutual cooperation in alliances is not automatic because, in the absence of trust, individual firms may be guided by their self-interest both before and after joining an alliance. Management researchers (e.g., Parkhe, 1993; Birnbirg, 1998) have emphasized the importance of structural controls to dampen opportunistic actions in alliances. In particular, Parkhe (1993) points out that the instability in strategic alliances arises from uncertainty regarding a partner's future behavior. His work suggests that careful planning at the "front end" can mitigate later problems; ex-ante attention to a structure can improve cooperative performance. Even though alliances may have a higher degree of opportunistic behavior by partners relative to integrated firms, many studies have documented cooperative 
behavior and potentially costly information sharing within partners (Browning et al., 1995; Cross, 1995; Chalos \& Sung, 1998; Chang et al., 2020).

The above findings are in stark contrast to the self-regarding/opportunistic behavior predicted by economic models. Given the apparent importance of trust and fairness in alliance relationships, some academics (Koza \& Lewin, 1998; Ariño et al., 2001) have called for more systematic research into the role of trust and fairness in business relations, observing that: "it is clear that research on trust and fairness needs to advance beyond a catch-all residual in the unexplained random error."

Our work is in the spirit of these suggestions. Accordingly, in this paper, we systematically examine the role of relationship variables such as trust and fairness in alliances and derive their economic value to alliance partners. More specifically, we develop a simple analytical model to address the following three research questions:

1) What is the alliance potential when partners deal fairly and trust each other?

2) What is the alliance potential when partners deal fairly but do not trust each other? and

3) What is the alliance potential when partners neither trust nor deal fairly with each other?

Our model is built around a simple two-partner alliance. An alliance is formed to take advantage of the synergies in the joint production. As a benchmark, we derive the alliance potential when both firms trust each other and deal fairly. Then we investigate the loss in alliance potential due to the loss of trust between alliance firms. Next, we investigate the incremental loss in alliance potential due to the failure of alliance partners to play fair with each other. Finally, we investigate a scenario where one of the partners takes the role of the dominant partner, a situation that resembles the standard principal-agent model.

Trust in our model implies that partners expect each other to exert the committed level of efforts even though one partner's effort is not observable by the other (Rotter, 1967; Morgan \& Hunt, 1994; Currall \& Inkpen, 2002). In other words, one's partner subordinates his/her self-interests to the "joint interests" of the alliance under most conceivable circumstances (Ariño et al., 2001). Fair dealing by alliance partners will further enhance the degree of trust and cooperation (Kumar, 1996; Robson et al., 2008). Fairness in an alliance can be evaluated over four different vectors: distributive fairness, procedural fairness, interpersonal fairness and informational fairness (Ariño \& Ring, 2010). In our study, we concentrate on distributive fairness, which implies that the output of the alliance is shared in proportion to the inputs of the individual partners (Luo, 2005; Ariño \& Ring, 2010). Therefore, in our model, with two symmetric firms, "fairness" implies that partners agree to share the alliance profits equally. Relying on trust and fairness may serve as a substitute for, or a complement to, more formal governance structures (Zaheer \& Venkatraman, 1995; Alvarez et al., 2004; Kanaga- 
retnam et al., 2018; Meer-Kooistra \& Vosselman, 2018; Kanagaretnam et al., 2019). Furthermore, if alliances built on mutual trust and fairness can succeed, then the deadweight loss on welfare imposed by costly incentive and monitoring systems can be avoided.

Our results show that, if the two alliance firms trust each other and agree to share profits equally, they will form an alliance irrespective of their level of synergy. Moreover, the alliance profit increases exponentially in the level of synergy. But when partners do not trust each other, the alliance profits are reduced by a large amount. This reduction is primarily due to the free-rider concern of each of the firms in the alliance. The absence of trust and the threat of opportunism reduce the level of effort put forward by partners. This reduction in alliance potential prevents some firms from coming together in an alliance, especially when synergies from joint production are low. The alliance potential is further destroyed if partners do not deal fairly with each other in addition to not trusting each other. This may be one of the main reasons why most alliances fail within a very short time. The lack of trust and fair play causes firms to fight for control. The fight may result in conflict between the two partners or the emergence of a dominant partner. In the pure conflict case, firms will refuse to come together irrespective of the level of synergy between them. In the dominant partner case, we show that only alliances with high levels of synergy will be formed. But even then, the dominant partner will realize only a small portion of the benefits from synergy.

The rest of the paper is organized as follows. In the following section, we present our model more formally and demonstrate how we introduce the conditions of trust and fairness in alliance relationships. Next, we discuss the major findings of our model. We conclude by discussing the contributions and limitations.

\section{The Model}

We begin with the basic single-period framework with two risk-neutral firms ${ }^{1}$, Firm 1 and Firm 2, contributing effort levels denoted by $e_{1}$ and $e_{2}$, respectively. The firm's gross cashflow $X_{i}$ is a function of the firm's effort $e_{i}$ and random factors beyond its control, $\varepsilon_{i}$. More specifically,

$$
X_{i}=e_{i}+\varepsilon_{i} ; E\left(\varepsilon_{i}\right)=0 \text { and } i=1,2 .
$$

We assume $\frac{e_{i}^{2}}{2}$ as the monetary equivalent cost of effort for each firm ${ }^{2}$. In the absence of an alliance, each firm chooses the effort level that maximizes the net cash flows, the difference between the gross cash flow and the individual cost of efforts. Accordingly, the individual efforts chosen by the firms and the ex-

\footnotetext{
${ }^{1}$ Although we investigate a two-firm alliance, some of the insights obtained from this analysis can easily be extended to alliances having more than two firms.

${ }^{2}$ As per standard agency models, effort is assumed to be exponential-Stevens and Thevaranjan (2010).
} 
pected net payoff equals 0.5 . Therefore, together both alliance firms would make a net cash flow of one. Hence, we consider the minimum payoff needed for the possibility of an alliance formation as one.

\section{Modeling the alliance relationship}

We assume the gross cash flow of the alliance to simply equal the addition of the two individual cash flows (additive model, Lambert, 2001). Hence, the alliance's gross cash flow $X$ is modeled as:

$$
X=e_{1}+e_{2}+\varepsilon_{1}+\varepsilon_{2} \text { and } E\left(\varepsilon_{1}, \varepsilon_{2}\right)=0
$$

The alliance production is influenced by effort levels of both partners and random factors beyond the alliance's control, $\varepsilon_{1}$ and $\varepsilon_{2}$. The assumption of an additive production function is reasonable, given the symmetric nature of efforts. Both firms know the production technology of the alliance reflected in equation [2]. After contracting, however, we assume that the effort contribution of other partner firm and, the random factors $\varepsilon_{1}$ and $\varepsilon_{2}$ are unobservable. The outcome of the alliance $X$ is observable by both firms.

Figure 1 presents the events in our model. In step 1, partner firms come together to discuss the effort contributions and sharing rules. In step 2, partners privately choose their effort levels. Finally, in step 3, alliance outcomes are realized and firms share the alliance profits according to the previously agreed upon sharing rule.

The trust and fair dealing between partners take the following meaning in our modeling. Trust means that each partner believes that the other partner will honor their word and choose the effort level they promised in step 1 (Rotter, 1967; Morgan \& Hunt, 1994; Currall \& Inkpen, 2002), when privately deciding on it in step 2. Fair dealing in our model means that in step 1, the two alliance firms agree to split the alliance profits equally. This formulation is reasonable given the symmetric nature of efforts (Luo, 2005; Ariño \& Ring, 2010).

Alliances are formed mainly to take advantage of synergies in joint production. We assume that alliance synergies reduce individual partner's cost of effort ${ }^{3}$ and we model this as:

$$
C_{i}=\frac{e_{i}^{2}-\mu e_{1} e_{2}}{2} ; \text { where } \mu \leq 1
$$

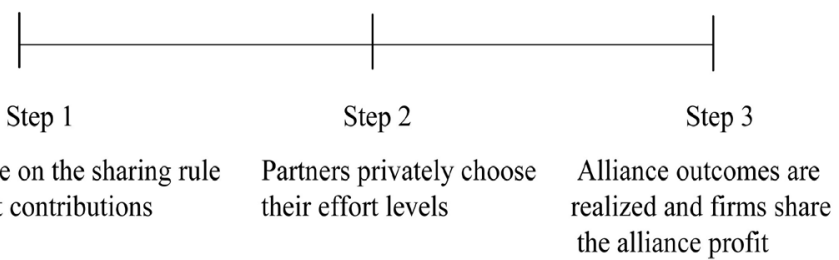

Figure 1. Timeline of events in the model.

${ }^{3}$ We obtain qualitatively similar results when we assume that synergies are realized in the production function instead of a reduction in cost of efforts, as assumed in this study. 
As before, we assume $\frac{e_{i}^{2}}{2}$ as the monetary equivalent cost of effort for each of the partners, but the cost is reduced by the realized synergies that we express as $\mu e_{1} e_{2}$, where $\mu$ is the level of synergy. Note that if $\mu=0$, then there are no synergies. On the other hand, a $\mu=1$ indicates maximum synergy as the total cost of alliance goes to zero when both firms choose the same level of effort.

Individual partners either pay or receive a participation fee to join the alliance (this also can be viewed as initial investment or payment) and get a share of alliance payoffs. Each partner's alliance payoffs can be expressed as:

For Firm 1:

$$
X_{1}=-\alpha+(1-\beta) X
$$

For Firm 2:

$$
X_{1}=\alpha+\beta X
$$

where, $\alpha$ is the initial payment and $\beta$ share of alliance benefit. Therefore, the net payoffs for the two firms are:

For Firm 1: $\Pi_{1}=-\alpha+(1-\beta) X-\left[\frac{e_{1}^{2}-\mu e_{1} e_{2}}{2}\right]$

For Firm 2: $\Pi_{2}=\alpha+\beta X-\left[\frac{e_{2}^{2}-\mu e_{1} e_{2}}{2}\right]$

For the Alliance: $\Pi=\Pi_{1}+\Pi_{2}=X-\left[\frac{e_{1}^{2}+e_{2}^{2}-2 \mu e_{1} e_{2}}{2}\right]$

The net payoffs for an individual partner are the difference between the alliance payoffs and the cost of effort for each partner firm. Since we assumed that both partner firms are risk-neutral, the expected utility for each firm (i.e., $U_{1}$ and $U_{2}$ ) will be the expected value of the net payoffs.

For Firm 1: $U_{1}=E\left(\Pi_{1}\right)=-\alpha+(1-\beta) E(X)-\left[\frac{e_{1}^{2}-\mu e_{1} e_{2}}{2}\right]$

For Firm 2: $U_{2}=E\left(\Pi_{2}\right)=\alpha+\beta E(X)-\left[\frac{e_{2}^{2}-\mu e_{1} e_{2}}{2}\right]$

The alliance net payoffs will be the sum of individual partners' payoffs. A key question in formulating the alliance problem is the objective function of the alliance partners-whether they want to maximize the joint surplus or be more concerned about the individual payoffs at the expense of joint considerations. Clearly, the answer to this question depends on how fairly the alliance partners agree to share the incremental profits from the alliance. Introducing $\delta$ as the degree of fairness with which Firm 1 treat Firm 2, we model the objective function of the alliance as $G=\Pi_{1}+\delta \Pi_{2}$ and Partner 1 and 2's share of the alliance profits as $\Pi_{1}=\frac{1}{2}+\frac{1}{1+\delta}(\Pi-1)$ and $\Pi_{2}=\frac{1}{2}+\frac{\delta}{1+\delta}(\Pi-1)$ respectively. Note that when $\delta=1$, Firm 1 treats Firm 2 fairly by sharing equally the incremental profits and the alliance objective function maximizes the alliance profits. On the 
other hand, when $\delta=0$, Firm 1 provides only the reservation level of profits to Firm 2, and this complete disregard for Firm 2's payoffs is also reflected in the alliance objective function. An intermediate value for $\delta(0<\delta<1)$ denotes the degree of fairness of Firm 1.

Irrespective of the degree of fairness, the alliance's objective is achieved by inducing both partners to contribute optimal levels of efforts $e_{1}$ and $e_{2}$ through the selection of $\alpha$ and $\beta$. We formally introduce the alliance problem as:

Alliance Problem:

$$
\underset{\alpha, \beta}{\operatorname{aaximiz}} E(G)=E\left(\Pi_{1}+\delta \Pi_{2}\right)
$$

Subject to:

$$
\begin{gathered}
\Pi_{1}=\frac{1}{2}+\frac{1}{1+\delta}(\Pi-1), \\
\Pi_{2}=\frac{1}{2}+\frac{\delta}{1+\delta}(\Pi-1) \\
e_{1} \in \operatorname{Arg} \max \left[-\alpha+(1-\beta) E(X)-\left(\frac{e_{1}^{2}-\mu e_{1} e_{2}}{2}\right)\right] \\
e_{2} \in \operatorname{Arg} \max \left[\alpha+\beta E(X)-\left(\frac{e_{2}^{2}-\mu e_{1} e_{2}}{2}\right)\right]
\end{gathered}
$$

The first constraint, [7] ensures that it is rational for each firm to participate in the alliance, given that each firm can get a net payoff of 0.5 on its own. The second constraint, [8] ensures that inducing effort level $e_{l}$ is incentive compatible (IC) for Firm 1. Similarly, the third constraint, [9] ensures that the choice of $e_{2}$ is incentive compatible for Firm 2. In the absence of trust and observability of efforts, it is necessary to have the IC constraints to ensure that each firm would contribute to the desired effort. However, if alliance firms trust each other, then there is no need for formal contracts, as partner firms would honor their promised effort contributions without any contracts. In this case, the IC constraints (i.e., [8] [9]) will become redundant. In the following section, we discuss several scenarios where we investigate the impact of trust and fairness in alliances.

\section{Implications of Trust and Fairness in Alliances}

We begin our analysis by deriving the alliance potential when both partners trust and deal fairly with each other. This case can be viewed as the "first-best" solution in alliances, since trust between partners will act as a substitute for incentive contracts and would neutralize potential moral hazard problems. Thus, the need for IC constraints given by equations [8] and [9] to induce the desired effort levels becomes redundant. Fair dealing between partners implies that $\delta=1$. Under these conditions, the alliance problem described in equations [6] - [9] will reduce to:

$$
\underset{e_{1}, e_{2}}{\operatorname{Maximiz}} E(G)=E(\Pi)
$$


Subject to:

$$
\Pi_{1}=\Pi_{2}=\frac{1}{2}+\frac{1}{2}(\Pi-1)
$$

The solution to the above problem for the alliance profits and the individual effort contributions are shown in Figure 2.

Proposition 1: If the two firms agree to share profits equally and trust each other to exert the committed level of effort, they will form an alliance irrespective of their level of synergy. Moreover, the alliance profit increases exponentially in the level of synergy and approaches infinity when $\mu=1$. See Figure 2.

The alliance profit is given by $\Pi=\frac{1}{1-\mu}$.

Proof: All proofs are in the Appendix.

The intuition behind Proposition 1 is as follows. Symmetric firms dealing fairly with each other will contribute an equal amount of effort towards the alliance. The synergy drives the marginal cost of effort down for each firm. At the extreme, when $\mu=1$, the marginal cost of effort becomes zero. On the other hand, the marginal benefit of effort remains unaffected by the alliance. As such, the optimal level of effort increases with the level of synergy and improves the alliance profit accordingly.

In the next set of results, we investigate the loss in alliance potential due to the lack of trust between partners. In the absence of trust, the partners need to ensure that promised effort contributions are exerted. To do so, one incentive compatible (IC) constraint for each partner (Equations [8] and [9]) is needed so that partners put forth desired levels of effort. We assume that partners continue to deal fairly with each other. In this case, the alliance problem can be stated as:

$$
\underset{\alpha, \beta}{\operatorname{Maximiz}} E(G)=E(\Pi)
$$

Subject to:

$$
\begin{gathered}
\Pi_{1}=\Pi_{2}=\frac{1}{2}+\frac{1}{2}(\Pi-1) \\
e_{1} \in \operatorname{Arg} \max \left[-\alpha+(1-\beta) E(X)-\left(\frac{e_{1}^{2}-\mu e_{1} e_{2}}{2}\right)\right]
\end{gathered}
$$

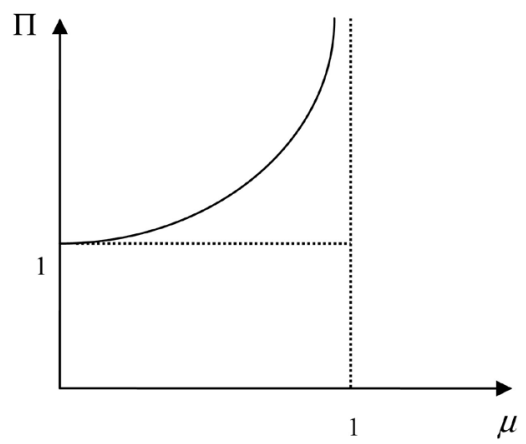

Figure 2. Alliance potential when firms deal fairly and trust each other. 


$$
e_{2} \in \operatorname{Arg} \max \left[\alpha+\beta E(X)-\left(\frac{e_{2}^{2}-\mu e_{1} e_{2}}{2}\right)\right]
$$

Solution to the above problem for the alliance profits is shown in Figure 3.

Proposition 2: Suppose the two firms agree to share profits equally but do not trust each other to exert the committed level of effort, the alliance will not form if the level of synergy is below a critical value $(\mu \leq 0.382)$. And even when they form an alliance $(\mu>0.382)$, there will be a significant drop in the alliance profits. The drop in profits due to lack of trust increases in the level of synergy. See Figure 3.

The alliance profit, in this case, is given by

$$
\Pi=\frac{3-\mu}{4(1-0.5 \mu)^{2}} \text { for } \mu>0.382 \text {. }
$$
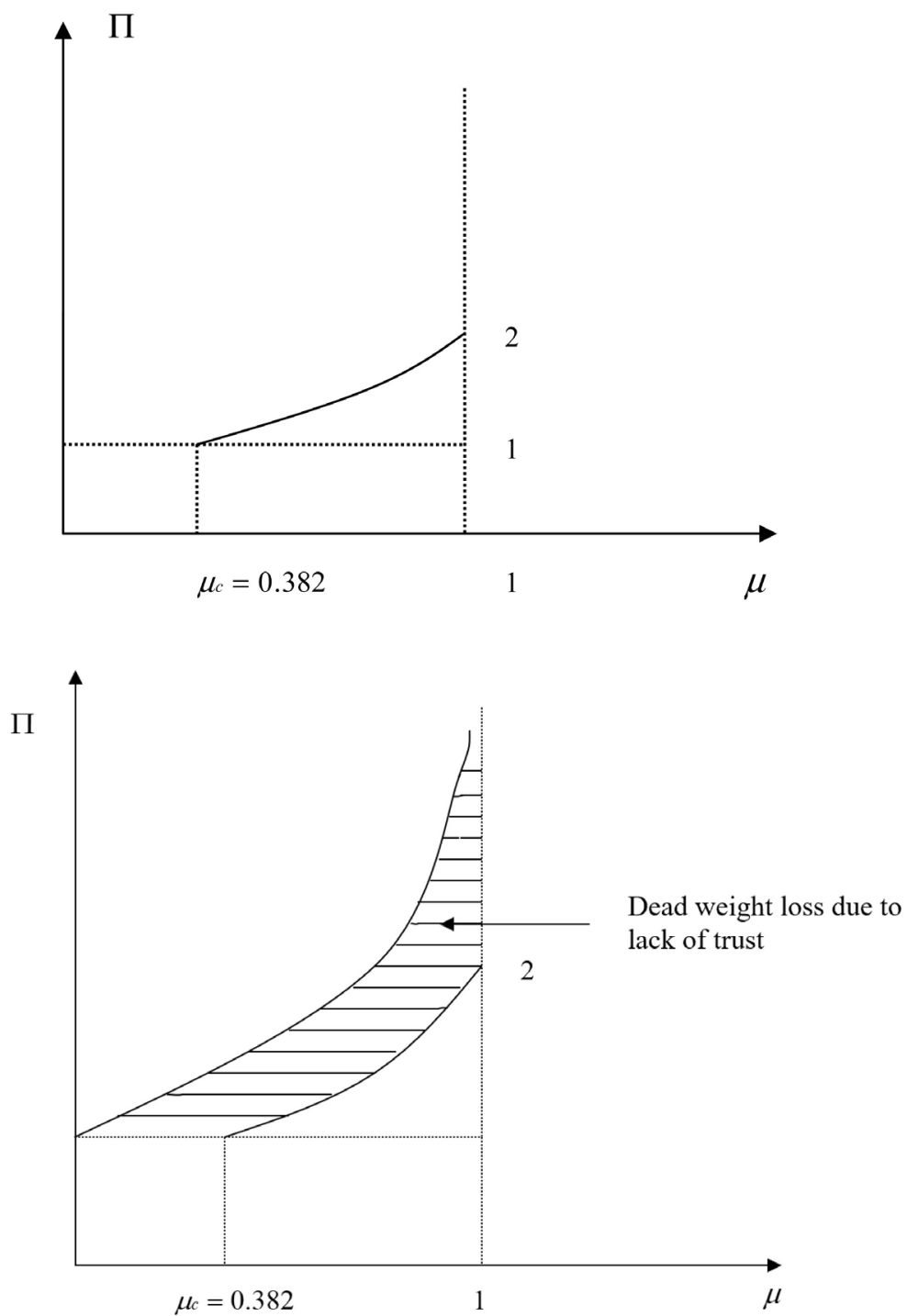

Figure 3. Alliance potential when firms deal fairly but do not trust each other. 
The problem here is that the lack of trust gives rise to a free-rider concern. Each firm knows that the other has incentives to free-ride on their hard work. For example, Firm 1 knows that if it exerts the level of effort that is optimal under the trust and fairness regime, the Firm 2 has incentives to shirk to a lower level of effort. The marginal cost savings from effort is higher than the marginal losses from their share of profits at this point. However, as the level of effort decreases, the marginal cost savings from reduced effort decreases while the marginal losses from benefits remain the same. The equilibrium therefore is reached at the point where the marginal cost savings from effort is the same as marginal losses from their share of profits. In other words, the lack of trust forces the firms to work at a much lower level causing significant losses in alliance profits. This is also why the two firms will not form the alliance if their synergy is not high enough. In this case, the benefit from synergy will be outweighed by the loss of efficiency due to mutual mistrust.

Next, we investigate the general scenario where the alliance firms neither trust nor deal fairly with each other. Specifically, Firm 1 does not treat Firm 2 fairly, i.e., $\delta<1$.

Proposition 3: When partners do not trust each other and Firm 1 (the dominant one) does not treat Firm 2 fairly, the formation of alliance requires the level of synergy to exceed a significantly higher critical value. Moreover, when they form an alliance, the lack of fair play causes a further reduction in the alliance profit. Both the critical level of synergy and the drop in alliance profits increase as the degree of fairness decrease. Moreover, the alliance will not form if the degree of fairness goes below a critical level.

Here, the partners do not trust each other, as such, the effort levels are low to begin with. Moreover, given that the dominant partner takes a bigger share of the alliance profits, the weaker partner becomes less motivated and reduces further his or her effort. The problem is magnified as the degree of fairness gets smaller. This problem is similar to a standard principal-agent model.

But the double-sided moral hazard brings about tensions that are not present in the typical principal-agent model. For example, if Firm 1 completely dominates Firm 2, the alliance will not form at all. Such an arrangement will motivate only a lower level of effort from the agent and require a higher level of effort from the principal. On the other hand, the principal can lower his level of effort and yet improve the size of the pie if he is willing to share more of the pie with the agent. In other words, it is in Firm 1's best interest to treat Firm 2 with some degree of fairness. The solution to this problem for the individual firm's returns is shown in Figure 4.

It is true that in many situations in the real world, one firm may emerge as the dominant partner and other may accept it. But we do not believe that all of these situations will lead to the above equilibrium because individuals care about fairness. In our example, the more, the weaker firm cares about fairness, the greater the dominant firm has to share to induce participation. In the extreme, if the 

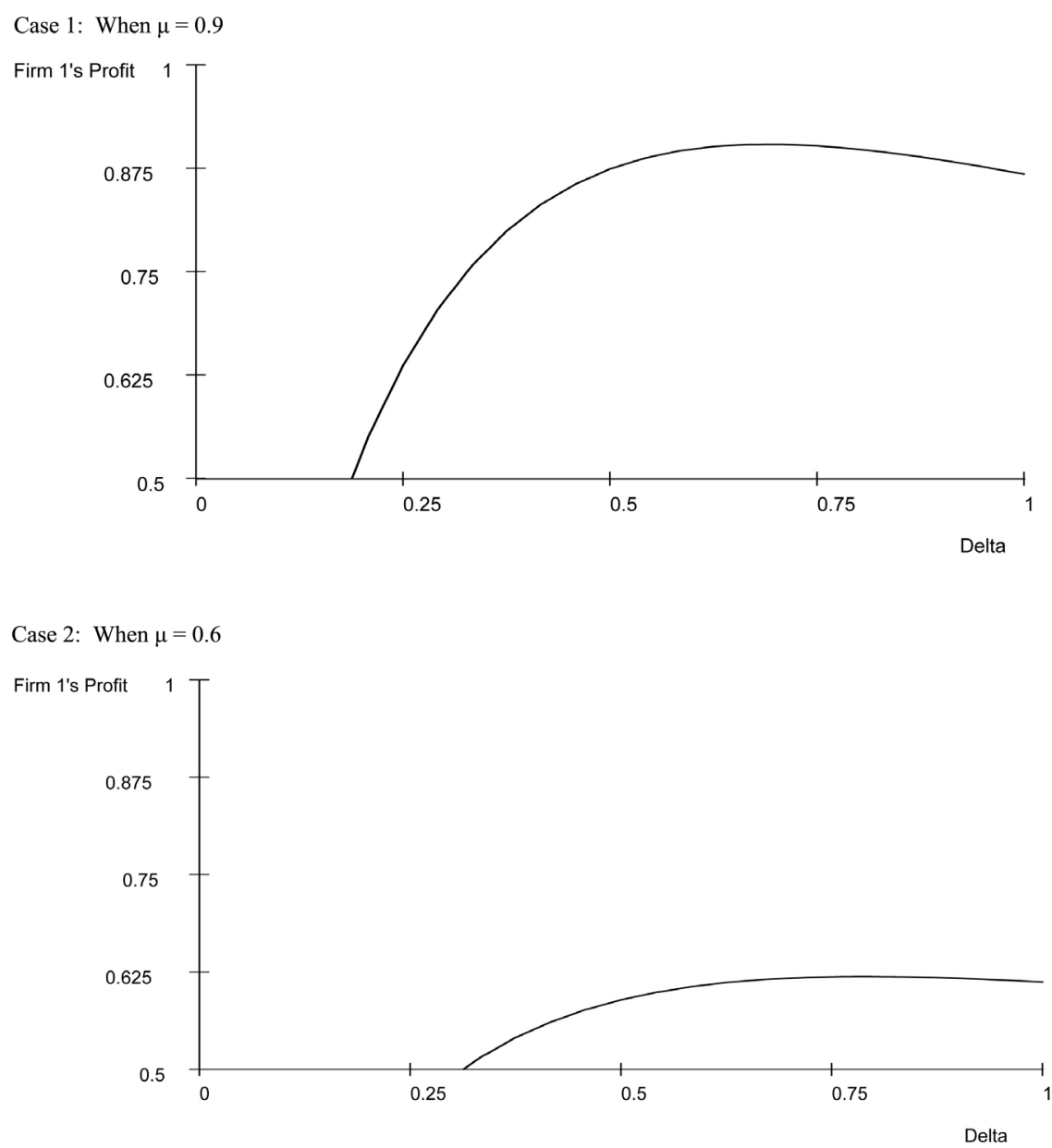

Figure 4. Dominant partner's profit.

second firm refuses to accept a weaker position, then the alliance will not form at all.

Proposition 4: Suppose the two firms do not trust each other and fights for a bigger share of the alliance profits, then the alliance will not form at all irrespective of the level of synergy.

Here, each firm, instead of sharing equally the alliance profits begins to fight for increasing their share of the pie. In this process, each firm has incentives to take a tougher bargaining position than the other. The end result is a prisoners' dilemma problem where the only equilibrium is not to come together at all. This is a classic example of the weaknesses in the extant agency models. In the absence of any value for fair play, wealth-maximizing agents, in their desire to gain a little more than the other foregoes the whole pie irrespective of how large the pie is. We believe that real-world agents care not only for wealth but also for fairness in their dealings with each other. As a result, in the situation that we have described in this paper (two identical firms), their desire for fairness will sustain the 50 - 50 profit sharing equilibrium. But this is not to say that the firms will not form the alliance unless they care about fairness. 


\section{Conclusion}

In this paper, we develop an analytical model to illustrate the role of trust and fairness in alliances and quantify their economic value to alliance partners. We show that alliance profits and the individual firms' profits are greatest when partners trust and deal fairly with each other. Moreover, trusting and fair dealing partners benefit the most from the synergies of joint production. We also show that when partners do not trust each other, the alliance profits are reduced by a large amount. This reduction is primarily due to the free-rider concern of each of the firms in the alliance. This reduction in alliance potential prevents some firms from coming together in an alliance, especially when synergies from joint production are low. The alliance potential is further destroyed if partners do not deal fairly in addition to not trusting each other. We investigate two possibilities under this scenario: either the emergence of a dominant partner or the partners end up in conflict, fighting for a higher share of the alliance profits. In the pure conflict case, firms will refuse to come together irrespective of the level of synergy between them. In the dominant partner case, only firms with high levels of synergy will agree to come together. But even then, the dominant partner will be able to realize only a small portion of the benefits from synergy. Our model demonstrates that the benefits from contractual mechanisms are much smaller compared to the alliance potential when partners deal fairly and trust each other. We also show that the lack of trust and greed would limit the number of alliances that may survive in the long run, even in the presence of synergies that can be exploited by alliance partners. This may be one of the main reasons why most alliances fail within a very short period.

We believe that our model makes several important contributions to the vast literature on business alliances. First, we demonstrate the economic significance of trust and fairness in an alliance setting. Our model can be used to quantify the welfare loss due to lack of trust and fairness in alliances. Second, we are able to capture the interplay of trust and fairness with synergy. Therefore, firms interested in partnering should not only focus on potential synergies on production and/or cost savings in alliances but also on relationship factors such as trustworthiness and fair dealing of other partners. Finally, we point out the importance of partners' consideration for each other's payoffs in an alliance. This is a classic example of the weaknesses in the extant agency models. In the absence of any value for fair play, wealth-maximizing agents, in their desire to gain a little more than the other foregoes the whole pie irrespective of how large the pie is.

Among the limitations of our model are that it is not dynamic in the sense of capturing equilibrium strategies over multiple periods. Alliance firms may learn over time that rewards from cooperative outcomes are greater than rewards from self-interested behavior. Also, the incentive for an alliance firm to build a good reputation may work against the incentive to free-ride. Repeated interactions provide the basis for partners to develop trust in alliance relationships. 


\section{Conflicts of Interest}

The authors declare no conflicts of interest regarding the publication of this paper.

\section{References}

Alvarez, S. A., Barney, J. B., \& Bosse, D. A. (2004). Trust and Its Alternatives. Human Resource Management, 42, 393-404. https://doi.org/10.1002/hrm.10097

Anderson, E., \& Weitz, B. (1989). Determinants of Continuity in Conventional Industrial Channel Dyads. Marketing Science, 8, 310-323. https://doi.org/10.1287/mksc.8.4.310

Ariño, A., \& Ring, P. S. (2010). The Role of Fairness in Alliance Formation. Strategic Management Journal, 31, 1054-1087. https://doi.org/10.1002/smj.846

Ariño, A., de la Torre, J., \& Ring, P.S. (2001). Relational Quality: Managing Trust in Corporate Alliances. California Management Review, 44, 109-131. https://doi.org/10.2307/41166113

Birnbirg, J. G. (1998). Control in Interfirm Cooperative Relationships. Journal of Management Studies, 35, 421-428. https://doi.org/10.1111/1467-6486.00102

Bleeke, J., \& Ernst, D. (1995). Is Your Strategic Alliance Really a Sale. Harvard Business Review, 73, 97-105.

Browning, L. D., Beyer, J. M., \& Shelter, J. C. (1995). Building Cooperation in a Competitive Industry: SEMATECH and the Semiconductor Industry. Academy of Management Journal, 38, 113-151.

Chalos, P., \& Sung, J. (1998). Outsourcing Decisions and Managerial Incentives. Decision Sciences, 29, 901-919. https://doi.org/10.1111/j.1540-5915.1998.tb00881.x

Chan, S. H., Kensinger, J. W., Keown, A. L., \& Martin, J. D. (1997). Do Strategic Alliances Create Value. Journal of Financial Economics, 46, 199-221. https://doi.org/10.1016/S0304-405X(97)00029-9

Chang, H., Fernando, G. D., Srinivasan, D., \& Tripathy, A. (2020). Productivity Spillovers in Supply Chain Networks. International Journal of Accounting Auditing and Performance Evaluation, 16, 230-248. https://doi.org/10.1504/IJAAPE.2020.112713

Croonen, E. (2010). Trust and Fairness during Strategic Change Processes in Franchise Systems. Journal of Business Ethics, 95, 191-209. https://doi.org/10.1007/s10551-009-0354-Z

Cross, J. (1995). I.T. Outsourcing: British Petroleum. Harvard Business Review, 73, 95-102.

Currall, S. C., \& Inkpen, A. C. (2002). A Multilevel Approach to Trust in Joint Ventures. Journal of International Business Studies, 33, 479-495. https://doi.org/10.1057/palgrave.jibs.8491027

Dwyer, F. R., Schurr, P. H., \& Oh, S. (1987). Developing Buyer-Seller Relationships. Journal of Marketing, 51, 11-27. https://doi.org/10.1177/002224298705100202

Gomes, E., Barnes, B. R., \& Mahmood, T. (2016). A 22 Year Review of Strategic Alliance Research in the Leading Management Journals. International Business Review, 25, 15-27. https://doi.org/10.1016/j.ibusrev.2014.03.005

Ireland, R. D., Hitt, M. A., \& Vaidyanath, D. (2002). Alliance Management as a Source of Competitive Advantage. Journal of Management, 28, 413-446. https://doi.org/10.1177/014920630202800308

Kale, P., \& Singh, H. (2009). Managing Strategic Alliances: What Do We Know Now, and Where Do We Go from Here? Academy of Management Perspectives, 23, 45-62. 
https://doi.org/10.5465/amp.2009.43479263

Kanagaretnam, K., Lee, J., Lim, C. Y., \& Lobo, G. J. (2018). Societal Trust and Corporate Tax Avoidance. Review of Accounting Studies, 23, 1588-1628. https://doi.org/10.1007/s11142-018-9466-y

Kanagaretnam, K., Lobo, G. J., Wang, C., \& Whalen, D. J. (2019). Cross-Country Evidence on the Relationship between Societal Trust and Risk-Taking by Banks. Journal of Financial and Quantitative Analysis, 54, 275-301. https://doi.org/10.1017/S0022109018000455

Koza, M. P., \& Lewin, A. Y. (1998). The Co-Evolution of Strategic Alliances. Organization Science, 9, 255-264. https://doi.org/10.1287/orsc.9.3.255

Krishnan, R., Martin, X., \& Noorderhaven, N. G. (2006). When Does Trust Matter to Alliance Performance? Academy of Management Journal, 49, 894-917. https://doi.org/10.5465/amj.2006.22798171

Kumar, N. (1996). The Power of Trust in Manufacturer-Retailer Relationships. Harvard Business Review, 74, 92-105.

Kumar, N., Scheer, L. K., \& Steenkamp, J. B. E. (1995). The Effects of Perceived Interdependence on Dealer Attitudes. Journal of Marketing Research, 32, 348-356. https://doi.org/10.1177/002224379503200309

Lambert, R. A. (2001). Contracting Theory and Accounting. Journal of Accounting and Economics, 32, 3-87. https://doi.org/10.1016/S0165-4101(01)00037-4

Lerner, J., \& Merges, R.P. (1998). The Control of Technology Alliances: An Empirical Analysis of the Biotechnology Industry. The Journal of Industrial Economics, 46, 125156. https://doi.org/10.1111/1467-6451.00066

Li, L. W., Jiang, F. F., Pei, Y. L., \& Jiang, N. Q. (2017). Entrepreneurial Orientation and Strategic Alliance Success: The Contingency Role of Relational Factors. Journal of Business Research, 72, 46-56. https://doi.org/10.1016/j.jbusres.2016.11.011

Luo, Y. (2005). How Important Are Shared Perceptions of Procedural Justice in Cooperative Alliances? Academy of Management Journal, 48, 695-709. https://doi.org/10.5465/amj.2005.17843946

Meer-Kooistra, J., \& Vosselman, E. G. J. (2018). Trust and Control in Strategic Alliances: An Instrumental Perspective. In T. K. Das (Ed.), Managing Trust in Strategic Alliances (pp. 171-199). Charlotte, NC: Information Age Publishing.

Morgan, R. M., \& Hunt, S. D. (1994). The Commitment-Trust Theory of Relationship Marketing. Journal of Marketing, 58, 20-38. https://doi.org/10.1177/002224299405800302

Parkhe, A. (1993). Strategic Alliance Structuring: A Game Theoretic and Transaction Cost Examination of Interfirm Cooperation. Academy of Management Journal, 36, 794-829.

Parkhe, A. (1998). Building Trust in International Alliances. Journal of World Business, 33, 417-437. https://doi.org/10.1016/S1090-9516(99)80083-2

Poppo, L., Zhou, K. Z., \& Li, J. J. (2016). When Can You Trust “Trust”? Calculative Trust, Relational Trust, and Supplier Performance. Strategic Management Journal, 37, 724-741. https://doi.org/10.1002/smj.2374

Ring, P. S., \& Van de Ven, A. H. (1992). Structuring Cooperative Relationships between Organizations. Strategic Management Journal, 13, 483-498. https://doi.org/10.1002/smj.4250130702

Robson, M. J., Katsikeas, C. S., \& Bello, D. C. (2008). Drivers and Performance Outcomes of Trust in International Strategic Alliances: The Role of Organizational Complexity. 
Organization Science, 19, 647-665. https://doi.org/10.1287/orsc.1070.0329

Rotter, J. B. (1967). A New Scale for the Measurement of Interpersonal Trust. Journal of Personality, 35, 651-665. https://doi.org/10.1111/j.1467-6494.1967.tb01454.x

Russo, M., \& Cesarani, M. (2017). Strategic Alliance Success Factors: A Literature Review on Alliance Lifecycle. International Journal of Business Administration, 8, 1-9. https://doi.org/10.5430/ijba.v8n3p1

Stevens, D. E., \& Thevaranjan, A. (2010). A Moral Solution to the Moral Hazard Problem. Accounting, Organizations and Society, 35, 125-139. https://doi.org/10.1016/j.aos.2009.01.008

Zaheer, A., \& Venkatraman, N. (1995). Relational Governance as an Interorganizational Strategy: An Empirical Test of the Role of Trust in Economic Exchanges. Strategic Management Journal, 16, 373-392. https://doi.org/10.1002/smj.4250160504

Zineldin, M., Fujimoto, H., Li, Y., Kassean, H., Vasicheva, V., \& Yu, W. F. (2015). Why Do Both Marriages and Strategic Alliances Have over 50\% Failure Rate? A Study of Relationship Quality of Strategic Alliances in China, Japan and Mauritius. International Journal of Strategic Business Alliances, 4, 1-23.

https://doi.org/10.1504/IJSBA.2015.069305 


\section{Appendix}

\section{1) An individual firm's payoffs}

An individual Firm's production function $X_{i}=e_{i}+\varepsilon_{i} ; i=1,2$.

An individual Firm's cost of effort $C_{i}=\frac{e_{i}^{2}}{2}, i=1,2$.

Therefore Profit for each firm $\prod_{i}=X_{i}-C_{i}, i=1,2$.

Therefore, an Individual Firm's Problem is to

$$
\begin{gathered}
\operatorname{Max}_{e_{i}} E\left(\prod_{i}\right) \\
\Rightarrow e_{i}^{*}=1 \text { and } \prod_{i}^{*}=\frac{1}{2}
\end{gathered}
$$

$\therefore$ Total Profits for both Firms $\Pi=\Pi_{1}+\Pi_{2}=1$

Therefore, we consider $\Pi=1$ as the minimum pay-off needed for alliance formation.

2) Alliance potential when firms deal fairly and trust each other Alliance Production Function

$$
X=e_{1}+e_{2}+\varepsilon_{1}+\varepsilon_{2}
$$

Since there is fair sharing

$$
X_{i}=\frac{X}{2}
$$

From Equation (3),

$$
C_{i}=\frac{e_{i}^{2}}{2}-\frac{1}{2} \mu e_{1} e_{2} ; \mu \leq 1
$$

Alliance objective is to

$$
\underset{e_{1}, e_{2}}{\operatorname{Maximiz}}(G)=E(\Pi)
$$

Subject to:

$$
\begin{aligned}
& \Pi_{1}=\Pi_{2}=\frac{1}{2}+\frac{1}{2}(\Pi-1) \\
& \Rightarrow \operatorname{Max}_{e_{1}, e_{2}} e_{1}+e_{2}-\frac{e_{1}^{2}}{2}-\frac{e_{2}^{2}}{2}+\mu e_{1} e_{2}
\end{aligned}
$$

From First Order Conditions

$$
\begin{gathered}
\left.\Rightarrow \begin{array}{c}
1-e_{1}+\mu e_{1}=0 \\
1-e_{2}+\mu e_{2}=0
\end{array}\right\} e_{1}=e_{2}=\frac{1}{1-\mu} \\
\therefore \Pi=\Pi_{1}+\Pi_{2}=\frac{1}{1-\mu}
\end{gathered}
$$

3) Alliance potential when firms deal fairly but do not trust each other In the absence of trust we need contracts to induce desired effort With Fixed pay $\alpha$ and Incentive pay $\beta$

The payoff for Firm 1: $X_{1}=-\alpha+(1-\beta) X$ The payoff for Firm 2: $X_{2}=\alpha+\beta X$ 
Profit for Firm 1: $\Pi_{1}=-\alpha+(1-\beta) X-\left[\frac{e_{1}^{2}-\mu e_{1} e_{2}}{2}\right]$

Profit for Firm 2: $\Pi_{2}=\alpha+\beta X-\left[\frac{e_{2}^{2}-\mu e_{1} e_{2}}{2}\right]$

Therefore the alliance problem is to:

$$
\underset{\alpha, \beta}{\operatorname{Maximiz}} E(G)=E(\Pi)
$$

Subject to:

$$
\begin{gathered}
\Pi_{1}=\Pi_{2}=\frac{1}{2}+\frac{1}{2}(\Pi-1) \\
e_{1} \in \operatorname{Arg} \max \left[-\alpha+(1-\beta) E(X)-\left(\frac{e_{1}^{2}-\mu e_{1} e_{2}}{2}\right)\right] \\
e_{2} \in \operatorname{Arg} \max \left[\alpha+\beta E(X)-\left(\frac{e_{2}^{2}-\mu e_{1} e_{2}}{2}\right)\right]
\end{gathered}
$$

From IC conditions:

$$
\begin{aligned}
& (1-\beta)-e_{1}+\frac{\mu e_{2}}{2}=0 \\
& \beta-e_{2}+\frac{\mu e_{1}}{2}=0 \\
& \Rightarrow e_{1}-\frac{\mu e_{2}}{2}=1-\beta \\
& \frac{-\mu e_{1}}{2}+e_{2}=\beta \\
& e_{1}=\frac{(1-\beta)+\beta \frac{\mu}{2}}{1-\frac{\mu^{2}}{4}} ; \\
& e_{2}=\frac{\beta+\frac{\mu}{2}(1-\beta)}{1-\frac{\mu^{2}}{4}}
\end{aligned}
$$

Since Alliance has fair sharing it is easy to show that $\beta=0.5$

Therefore

$$
\begin{aligned}
& e_{1}=e_{2}=\frac{1}{2\left(1-\frac{\mu}{2}\right)} \\
& \therefore \Pi=\frac{3-\mu}{4\left(1-\frac{\mu}{2}\right)^{2}}
\end{aligned}
$$

When $\mu=1 ; \Pi=2$

When $\Pi=1$, let $\mu=\mu_{c}$, the minimum synergy needed to form the alliance 


$$
\begin{aligned}
& \therefore \frac{3-\mu_{c}}{4\left(1-\frac{\mu_{c}}{2}\right)^{2}}=1 \\
& \therefore \mu_{c}=0.382
\end{aligned}
$$

When $\mu<\mu_{c}$ the alliance will not form.

4) Alliance potential when partners neither trust nor deal fairly

a) Dominant partner's (Firm 1's) problem

$$
\underset{\alpha, \beta}{\operatorname{Maximiz}} E(G)=E\left(\Pi_{1}+\delta \Pi_{2}\right)
$$

Subject to:

$$
\begin{gathered}
\Pi_{1}=\frac{1}{2}+\frac{1}{1+\delta}(\Pi-1) \\
\Pi_{2}=\frac{1}{2}+\frac{\delta}{1+\delta}(\Pi-1) \\
e_{1} \in \operatorname{Arg} \max \left[-\alpha+(1-\beta) X-\left(\frac{e_{1}^{2}-\mu e_{1} e_{2}}{2}\right)\right] \\
e_{2} \in \operatorname{Arg} \max \left[\alpha+\beta X-\left(\frac{e_{2}^{2}-\mu e_{1} e_{2}}{2}\right)\right]
\end{gathered}
$$

From IC conditions (As in the previous case)

$$
\begin{aligned}
& e_{1}=\frac{(1-\beta)+\beta \frac{\mu}{2}}{1-\frac{\mu^{2}}{4}} \\
& \left.e_{2}=\frac{\beta+\frac{\mu}{2}(1-\beta)}{1-\frac{\mu^{2}}{4}}\right\} \quad e_{1}+e_{2}=\frac{1}{1-\frac{\mu}{2}}
\end{aligned}
$$

\section{Therefore the Dominant Partner's Problem is}

$$
\begin{aligned}
& \operatorname{Max}_{\alpha, \beta}-\alpha+(1-\beta)\left(e_{1}+e_{2}\right)-\left(\frac{e_{1}^{2}-\mu e_{1} e_{2}}{2}\right)+\delta\left[\alpha+\beta\left(e_{1}+e_{2}\right)-\left(\frac{e_{2}^{2}-\mu e_{1} e_{2}}{2}\right)\right] \\
& \Rightarrow \operatorname{Max}_{\alpha, \beta} \alpha(\delta-1)+\frac{1-\beta+\delta \beta}{1-\frac{\mu}{2}}-\frac{e_{1}^{2}}{2}-\frac{\delta e_{2}^{2}}{2}+\frac{1+\delta}{2} \mu e_{1} e_{2}
\end{aligned}
$$

Differentiating w.r.t $\beta$

$$
\begin{aligned}
& \Rightarrow \frac{-1+\delta}{1-\frac{\mu}{2}}-e_{1} \frac{\mathrm{d} e_{1}}{\mathrm{~d} \beta}-\delta e_{2} \frac{\mathrm{d} e_{2}}{\mathrm{~d} \beta}+\frac{(1+\delta) \mu}{2} \frac{\mathrm{d}\left(e_{1} e_{2}\right)}{\mathrm{d} \beta}=0 \\
& \Rightarrow \frac{-1+\delta}{1-\frac{\mu}{2}}+\frac{\left(1-\beta+\beta \frac{\mu}{2}\right)-\delta\left[\beta+\frac{\mu}{2}(1-\beta)\right]+\frac{1+\delta}{2} \mu\left(1-\frac{\mu}{2}\right)(1-2 \beta)}{\left(1-\frac{\mu^{2}}{4}\right)\left(1+\frac{\mu}{2}\right)}=0
\end{aligned}
$$




$$
\begin{array}{r}
\Rightarrow \beta=\frac{\delta-\frac{\mu}{2}}{\left(1-\frac{\mu}{2}\right)(1+\delta)} \\
\therefore e_{1}=\frac{1}{\left(1-\frac{\mu}{2}\right)(1+\delta)} \\
\therefore e_{2}=\frac{\delta}{\left(1-\frac{\mu}{2}\right)(1+\delta)} \\
\therefore e_{2}=\delta e_{1}
\end{array}
$$

The Alliance Profit is given by

$$
\Pi=\Pi_{1}+\Pi_{2}=e_{1}+e_{2}-\frac{e_{1}^{2}}{2}-\frac{e_{2}^{2}}{2}+\mu e_{1} e_{2}
$$

Since $e_{2}=\delta e_{1}$

$$
\begin{aligned}
& \Pi=e_{1}+e_{2}-\frac{e_{1}^{2}}{2}\left(1+\delta^{2}-2 \mu \delta\right) \\
& \therefore \Pi=\frac{2\left(1-\frac{\mu}{2}\right)(1+\delta)^{2}-\left(1-2 \mu \delta+\delta^{2}\right)}{2\left(1-\frac{\mu}{2}\right)^{2}(1+\delta)^{2}}
\end{aligned}
$$

Dominant Partner's Problem is to choose delta that maximizes its profit

$$
\begin{aligned}
& \operatorname{Max}_{\delta^{*}} \frac{1}{2}+(\Pi-1) \frac{1}{1+\delta} \\
& \Rightarrow \frac{\mathrm{d}}{\mathrm{d} \delta}\left[\frac{\Pi}{1+\delta}-\frac{1}{1+\delta}\right]
\end{aligned}
$$

But,

$$
\Pi=\frac{2\left(1-\frac{\mu}{2}\right)(1+\delta)^{2}-\left(1-2 \mu \delta+\delta^{2}\right)}{2\left(1-\frac{\mu}{2}\right)^{2}\left(1+\delta^{2}\right)} \equiv \frac{(1-\mu)+4 \delta+(1-\mu) \delta^{2}}{A(1+\delta)^{2}} ;
$$

where $A=2\left(1-\frac{\mu}{2}\right)^{2}$

$$
\begin{aligned}
& \Rightarrow \frac{\mathrm{d}}{\mathrm{d} \delta}\left[\frac{(1-\mu)}{A(1+\delta)^{3}}+\frac{4 \delta+(1+\mu) \delta^{2}}{A(1+\delta)^{3}}-\frac{1}{1+\delta}\right] \\
& \Rightarrow \frac{1}{A(1+\delta)^{4}}\left[3+\mu+\frac{\mu^{2}}{2}-2 \delta-6 \delta \mu+\mu^{2} \delta+\delta^{2}\left(1-\mu+\frac{\mu^{2}}{2}\right)\right]=0
\end{aligned}
$$

This equation does not have a closed from solution.

However, it is easy to show that when

Case 1 (Please see Figure 4): $\mu=0.9, \delta^{*}=0.514, \Pi^{*}=1.5737, \Pi_{1}^{*}=0.8790$, 
$\Pi_{2}^{*}=0.6948$ compared to a $\Pi^{*}=10$ and $\Pi_{1}^{*}=\Pi_{2}^{*}=5$ when partners trust each other and deal fairly; and

Case 1 (Please see Figure 4): $\mu=0.6, \delta^{*}=0.649, \Pi^{*}=1.1875$, $\Pi_{1}^{*}=0.6137, \Pi_{2}^{*}=0.5738$ compared to a $\Pi^{*}=2.5$ and $\Pi_{1}^{*}=\Pi_{2}^{*}=1.25$ when partners trust each other and deal fairly

\section{b) Conflict Situation}

Alliance problem is

$$
\begin{aligned}
& \operatorname{Max}_{\alpha, \beta} E\left[\delta_{2} \Pi_{1}+\delta_{1} \Pi_{2}\right] \\
& \Rightarrow \operatorname{Max}_{\alpha, \beta} \frac{1}{\delta_{2}} E\left[\Pi_{1}+k \Pi_{2}\right]
\end{aligned}
$$

where $k=\frac{\delta_{1}}{\delta_{2}}$

\section{Firm 1's Reaction function}

$$
\begin{aligned}
& \operatorname{Max}_{\delta_{1}} \frac{1}{2}+(\Pi-1) \frac{\delta_{2}}{\delta_{1}+\delta_{2}} \\
& \Rightarrow \operatorname{Max}_{\delta_{1}} \frac{1}{2}+(\Pi-1) \frac{1}{1+k} \\
& \Rightarrow \frac{\mathrm{d}}{\mathrm{d} k}\left[\frac{\Pi-1}{1+k}\right] \frac{\mathrm{d} k}{\mathrm{~d} \delta_{1}}=0 \\
& \Rightarrow \frac{1}{A+(1+k)^{4}}\left[3+\mu+\frac{\mu^{2}}{2}-2 k-6 k \mu+\mu^{2} k+k^{2}\left(1-\mu+\frac{\mu^{2}}{2}\right)\right] \frac{1}{\delta_{2}}=0
\end{aligned}
$$

Firm 2's Reaction function

$$
\begin{aligned}
& \operatorname{Max}_{\delta_{2}} \frac{1}{2}+(\Pi-1) \frac{\delta_{2}}{\delta_{1}+\delta_{2}} \\
& \Rightarrow \operatorname{Max} \frac{1}{2}+(\Pi-1) \frac{1}{1+k^{1}}
\end{aligned}
$$

where $k^{1}=\frac{\delta_{2}}{\delta_{1}}$

$$
\begin{aligned}
& \Rightarrow \frac{\mathrm{d}}{\mathrm{d} k}\left[\frac{\Pi-1}{1+k^{1}}\right] \frac{\mathrm{d} k^{1}}{\mathrm{~d} \delta_{2}}=0 \\
& \Rightarrow \frac{1}{A\left(1+k^{1}\right)^{4}}\left[3+\mu+\frac{\mu^{2}}{2}-2 k^{1}-6 k^{1} \mu+\mu^{2} k^{1}+k^{1}\left(1-\mu+\frac{\mu^{2}}{2}\right)\right] \frac{1}{\delta_{1}}=0
\end{aligned}
$$

Using Firm 1's and Firm 2's reaction functions we find that there are no solutions within the parameter values. 